\title{
DIFFICULTY TO ESTABLISH VEGETATIVE COMPATIBILITY OF JAPANESE ISOLATES OF VERTICILLIUM DAHLIAE KLEB. USING MELANIN-SYNTHESIS DEFICIENT MUTANTS
}

\author{
HIDEYUKI NAGAO,* DAI WAKATABE, AND TSUTOMU IIJIMA ${ }^{1}$ \\ Faculty of Horticulture, Chiba University, Matsudo 271, Japan \\ ${ }^{1}$ Tokyo Metropolitan Agricultural Experiment Station, Tachikawa 180, Japan
}

(Received February 1, 1994; Accepted July 14, 1994)

\begin{abstract}
Japanese isolates of Verticillium dahliae were formerly designated as tomato pathotype and non-tomato pathotype by pathogenicity tests. We attempted to classify 18 Japanese isolates based on vegetative compatibility. Only three isolates of the tomato pathotype induced compatible alm-brm mutants. A non-secreting brm mutant was not induced from isolate of the non-tomato pathotype. Complementation was not achieved by a pair of mutants from the tomato pathotype and those from the non-tomato pathotype. From these results, Japanese isolates of $\boldsymbol{V}$. dahliae could not be separated into any vegetative compatibility groups using melanin synthesis-deficient mutants.
\end{abstract}

Verticilium dahliae Kleb. is an important vascular wilt pathogen of various plant species. The fungus has been characterized by the pathogenicity in some plants $(7,22,24)$. In Japan, Verticillium wilt has been recognized from the early 1970s (15). Iijima categorized Japanese isolates of $V$. dahliae as "tomato pathotype" and "non-tomato pathotype" according to the pathogenicity on tomato (susceptible cultivar Beiju) (14). Hagiwara further proposed six groups for Japanese isolates based on pathogenicity for eggplant, tomato, pepper, Chinese cabbage, and soybean (9). Horiuchi et al. (13) have described a system for classifying Japanese $V$. dahliae isolates using a differential set of host plants. However, this differential host method is not conclusive. Employing a new differential host for the pathogenicity test with the formerly determined isolates, a new categorization would be possible. For example, parsley (33) and Chinese lantern plant (Physalis alkekengi var. franchetii) (14) showed more different susceptibilities than the host plants in proposed groups did. Increasing the kinds of

* Address reprint requests to: Dr. Hideyuki Nagao, Fuculty of Horticulture, Chiba University, 648 Matsudo, Matsudo 271, Japan. 
differential host plants may make the recognition of pathogenic groups more complicated. In addition, $V$. dahliae and $V$. albo-atrum do not clearly show host specificity as known in Fusarium with some exceptions $(12,17,22)$.

Heterokaryon formation is used as the criterion for compatibility of many imperfect fungi $(4,5,8,35)$. Heterokaryon compatibility groups suggested the existence of diverse genetic populations in imperfect fungi (6). It was examined by using complementary auxotrophic mutants $(23,31)$ or color mutants $(28)$. $V$. dahliae formed black microscletrotia where melanin granules concentrated in cell wall layers (36). Three albino mutants ( $\mathrm{alm}$ ) and four brown mutants ( $\mathrm{brm}$ ) were determined in their different mutants. Complemental relationships among these mutants were reported (2). No microsclerotia mutant ( $\mathrm{nms}$ ) does not form microsclerotia on the hypha and showed a white colony (2). Although $n m s$ also was one of the microsclerotial mutants, it is not complemental with either alm or brm. Heterokaryon compatibility groups were rephrased vegetative compatibility groups (VCGs) by Puhalla (29) and VCGs have been demonstrated in V. dahliae through the use of these microsclerotia color mutants induced with ultraviolet light. The defoliating and non-defoliating isolates from cotton were clearly distinguished into different VCGs (27). However many pathotypes of $V$. dahliae were considered to be vegetatively incompatible based on these kinds of mutants (29). Recently, pathotypes of $V$. dahliae previously designated as VCGs using microsclerotial color mutants were reassessed using nitrate non-utilizing (nit) mutants. It was reported that many pathotypes were found to be compatible using nit mutants $(19,20,32)$.

In this paper, we examined vegetative compatibility groups for Japanese isolates of $V$. dahliae using melanin-synthesis-deficient mutants and their relationships to the pathotypes that had been categorized by pathogenicity for the differential host plants.

\section{MATERIALS AND METHODS}

Cultural conditions. Isolates of Verticillium dahliae Kleb. and their sources are shown in Table 1. An isolate which was virulent on Crucifera (Chinese cabbage, radish, rape and so on) has been identified as $V$. dahliae var. longisporum (16) and as diploid $(13,18,21)$. Home-made potato-sucrose agar (PSA) was used for maintenance of isolates and determination of colony diameter. Potato-carrotdextrose agar (PCDA) and minimal medium (MM) were prepared according to Puhalla's method $(26,30)$. Instead of sanguinarine nitrate (29), $200 \mathrm{ppm}$ of sanguinarine sulfate was added to potato-dextrose-agar (PDA) (Difco Laboratories, Detroit, MI, U.S.A.) as the sanguinarine medium (25). To determine the loci of brm mutants, the tester mutants were grown on sucrose-nitrate agar and in 50 $\mathrm{ml}$ of liquid sucrose-nitrate medium in 250-ml Erlenmeyer flasks (2,3). All cultures were incubated at $25^{\circ} \mathrm{C}$ in darkness.

Induction of mutants. Conidia of each isolate were obtained from 14-day-old colonies. Scraped mycelia were suspended in $10 \mathrm{ml}$ of sterilized distilled water and 
Table 1. Characteristics of isolates of Verticillium dahliae.

\begin{tabular}{|c|c|c|c|}
\hline Isolate $^{a}$ & $\begin{array}{l}\text { Source of } \\
\text { isolation }\end{array}$ & $\begin{array}{c}\text { Growth rate } \\
\text { on } \text { PSA }^{b}\end{array}$ & $\begin{array}{l}\text { Tolerance to } \\
\text { sanguinarine }\end{array}$ \\
\hline $\mathrm{LE} 103(\mathrm{~T})^{d}$ & Tomato & 4.55 & 0.81 \\
\hline ST1 (T) & Potato & 4.40 & 0.25 \\
\hline HE6 (T) & Okra & 4.25 & 0.24 \\
\hline LE8602 (T) & Tomato & 3.65 & 0.77 \\
\hline${ }^{*} 84011(\mathrm{~T})(\mathrm{B})^{e}$ & Chinese cabbage & 2.98 & 0.67 \\
\hline CV1 (NT) & Watermelon & 5.15 & NT \\
\hline SM821 (NT) & Eggplant & 4.75 & 0.50 \\
\hline $22720(\mathrm{NT})$ & Chrysanthemum & 4.23 & 1.06 \\
\hline SM931 (NT) & Eggplant & 4.01 & NT \\
\hline $22710(\mathrm{NT})$ & Chrysanthemum & 3.87 & ND \\
\hline SM321 (NT) & Eggplant & 2.81 & NT \\
\hline AC406 (NT) & Udo & 2.34 & 0.92 \\
\hline *84034 (NT) (A) & Eggplant & 1.92 & 0.99 \\
\hline CM208 (NT) & Chrysanthemum & 1.53 & 0.96 \\
\hline *84023 (NT) (C) & Eggplant & 1.48 & 0.71 \\
\hline *84013 (NT) (D) & Chinese cabbage & 2.96 & NT \\
\hline *84010 (NT) (D) & Chinese cabbege & 1.86 & 0.41 \\
\hline *V316 (NT) (D) & Chinese cabbege & 3.02 & NT \\
\hline
\end{tabular}

a All isolates were identified and previously designated by Iijima (14). Isolates with an asterisk were kindly supplied by Hagiwara (9).

b All cultures were incubated at $25^{\circ} \mathrm{C}$ in darkness.

c The value was calculated by the formula; (colony diameter on PDA + sanguinarine)/(colony diameter on PDA). ND, isolate did not grow on PDA; NT, not tested.

d Tomato (Lycopersicon esculentum; cv. Beiju) was used as a differential host by Iijima (14). T, tomato pathotype; NT, non-tomato pathotype.

e A, B, C, and D represent the host specificity grouping according to Hagiwara (9).

filtered through a sterilized glass filter $(20-30 \mu \mathrm{m}$ pore size). The concentration of conidia was determined with a Thoma's hemacytometer and adjusted depending on the intensity of irradiation to obtain a survival curve. Conidia were spread on plates containing MM or PSA with a sterile glass rod. A sterilizing lamp (Toshiba GL15) was used as the source of ultraviolet (UV) light at $254 \mathrm{~nm}$. Dosage was measured with a Black-Ray ultraviolet intensity meter (UVP, Inc., U.S.A.). The average intensity of the UV light was ca. $20 \mathrm{ergs} / \mathrm{mm}^{2}$. After 10 days, the numbers of surviving colonies were counted and colonies were selected for their abnormalities in color and diffusion of pigments into the medium. Mutants were transferred on PSA two or three times because some of them slowly reverted to producing black microsclerotia. Mutants were verified by a single spore isolation and the color of the microsclerotia on PCDA was confirmed by visual and microscopic observations. Mutant phenotypes were designated with the genetic symbols albino microsclerotia mutant $(\mathrm{alm})$, brown microsclerotia mutant $(\mathrm{brm})$, and no microsclerotia mutant (nms) according to Bell et al. (2).

Pairing of color mutants. Pairings were made either between alm mutants or between an alm and a brm mutant. Colonies were grown for 14 days on PCDA. 
Mycelial blocks were cut with a 5-mm-diameter cork borer and paired $10 \mathrm{~mm}$ apart from each other on PCDA. Formation of a zone of black microsclerotia on the contact line was recognized as complementation. Each pairing was conducted at least twice. In some pairings, the cellophane method was used to examine exuding intermediates in the melanin biosynthetic pathway (27).

\section{RESULTS}

\section{Comparison of growth characteristics}

Growth rates among the isolates were almost similar on PSA at $25^{\circ} \mathrm{C}$. Tolerance to sanguinarine of some isolates of the tomato pathotype were very sensitive. On the other hand, most of the isolates among the non-tomato pathotype were resistant (Table 1).

Survival of $V$. dahliae with $U V$ irradiation and its frequency of melanin-deficient mutations

Eighteen isolates of $V$. dahliae were irradiated on $\mathrm{MM}$ with several different UV doses; $0.001 \%$ of colony survived at $5,000 \mathrm{ergs} / \mathrm{mm}^{2}$. The frequency of alm mutants of the tomato pathotype represented ca. $0.6 \%$ of the surviving colonies. However alm mutants from the non-tomato pathotype occurred less frequently $(<0.25 \%)$. All brm mutants of the non-tomato pathotype were the melanin intermediate secreting type. Brm mutants cultured on sucrose-nitrate medium did not markedly change the medium color that should reflect difference of loci (2). No stable mutant was obtained from diploid isolates (84010, 84013 and V316).

\section{Pairings of color mutants of tomato pathotype of $V$. dahliae}

Twenty-nine color mutants were induced by UV irradiation from five tomato pathotype (Table 2). For each isolate, complementations of alm and brm mutants were tried to be determined. Complementary alm-brm mutants were induced from LE103 (221, 222, 3103, 3104, 3123, and 3253), LE8602 (3503, 3506, and 3508), and ST1 $(8105,8109$, and 8112). For isolate HE6, all mutants obtained were $n m s$. Complementary mutants (tester) were selected in each isolate. Then we examined complementation between these mutants to determine the relationships among isolates of the tomato pathotype (Table 3). LE103 and LE8602 were complemented in all alm and brm combinations. LE103 and ST1 were complemented in certain alm and brm combinations. LE8602 and ST1 were complemented with both $\mathrm{brm}$ mutants. None of the mutants used secreted any melanin precursors. For isolate 84011, alm mutants obtained did not show any complementation toward these testers. Isolates LE103, LE8602, and ST1 of the tomato pathotype showed compatibility with each other. However, results of complemental reaction depended upon the mutants and isolates used. These results did not clearly show "tomato pathotype" as one of the diverse populations in $V$. dahlinae. 
Table 2. Nature of mutants of Verticillium dahliae by UV irradiation.

\begin{tabular}{|c|c|c|c|}
\hline Isolate & Mutant induced & $\begin{array}{l}\text { Dose of UV irradiation } \\
\left(\mathrm{erg} / \mathrm{mm}^{2}\right)\end{array}$ & $\begin{array}{c}\text { Designation of } \\
\text { phenotype }\end{array}$ \\
\hline \multirow[t]{11}{*}{ LE103 } & 221 & 14,400 & alm \\
\hline & 222 & 14,400 & alm \\
\hline & 3103 & 3,000 & brm \\
\hline & 3104 & 3,000 & alm \\
\hline & 3123 & 2,400 & alm \\
\hline & 3125 & 2,400 & $n m s$ \\
\hline & 3237 & 3,000 & $n m s$ \\
\hline & $3237 \mathrm{~S}$ & 3,000 & $n m s$ \\
\hline & 3239 & 3,000 & $n m s$ \\
\hline & 3253 & 3,000 & alm \\
\hline & 3287 & 3,000 & $n m s$ \\
\hline \multirow[t]{4}{*}{ ST1 } & 8105 & 4,600 & brm \\
\hline & 8109 & 4,600 & brm \\
\hline & 8112 & 4,600 & alm \\
\hline & 8132 & 4,600 & alm \\
\hline \multirow[t]{7}{*}{ HE6 } & 7101 & 3,800 & $n m s$ \\
\hline & 7102 & 3,800 & $n m s$ \\
\hline & 7105 & 3,800 & $n m s$ \\
\hline & 7108 & 3,800 & $n m s$ \\
\hline & 7110 & 3,800 & $n m s$ \\
\hline & $7110 \mathrm{~B}$ & 3,800 & $n m s$ \\
\hline & 7115 & 3,800 & $n m s$ \\
\hline \multirow[t]{3}{*}{ LE8602 } & 3503 & 3,040 & brm \\
\hline & 3506 & 3,040 & alm \\
\hline & 3508 & 3,040 & alm \\
\hline \multirow[t]{4}{*}{84011} & H4109 & 4,600 & alm \\
\hline & H4201 & 4,800 & alm \\
\hline & H4202 & 4,800 & alm \\
\hline & H4203 & 4,800 & alm \\
\hline CV1 & J201 & 4,800 & brm \\
\hline \multirow[t]{6}{*}{ SM821 } & 6201 & 3,008 & alm \\
\hline & 6208 & 3,008 & alm \\
\hline & 6217 & 3,008 & alm \\
\hline & 6230 & 3,008 & alm \\
\hline & 6240 & 2,700 & alm \\
\hline & 6244 & 2,700 & brm \\
\hline \multirow[t]{2}{*}{ SM931 } & 6301 & 3,000 & alm \\
\hline & 6302 & 3,760 & brm \\
\hline \multirow[t]{5}{*}{ AC406 } & 5201 & 2,400 & brm \\
\hline & 5203 & 7,008 & brm \\
\hline & 5205 & 4,512 & brm \\
\hline & 5209 & 4,640 & $n m s$ \\
\hline & 5210 & 4,640 & alm \\
\hline \multirow[t]{4}{*}{ CM208 } & 4211 & 4,560 & brm \\
\hline & 4305 & 4,640 & brm \\
\hline & 4401 & 4,800 & alm \\
\hline & 4402 & 4,800 & alm \\
\hline
\end{tabular}


Table 3. Complementation test among mutants of the tomato pathotype of Verticillium dahliae.

\begin{tabular}{|c|c|c|c|c|c|c|c|c|c|c|c|}
\hline & & \multicolumn{3}{|c|}{ LE103 } & \multicolumn{3}{|c|}{ LE8602 } & \multicolumn{4}{|c|}{ ST1 } \\
\hline & & 3123 & 3253 & $3103 *$ & 3506 & 3508 & $3503 *$ & 8112 & 8132 & $8105^{*}$ & $8109^{*}$ \\
\hline \multirow[t]{4}{*}{ LE103 } & 222 & -- & -- & $+t$ & -- & -- & ++ & -- & - & - & $\mathrm{NT}^{b}$ \\
\hline & 3123 & $* *$ & -- & ++ & -- & -- & ++ & -- & - & NT & NT \\
\hline & 3253 & & $* *$ & ++ & -- & -- & ++ & ++ & $t+$ & -- & ++ \\
\hline & $3103^{* a}$ & & & $* *$ & -- & -- & -- & ++ & ++ & ++ & -- \\
\hline \multirow[t]{3}{*}{ LE8602 } & 3506 & & & & $* *$ & -- & ++ & -- & -- & -- & NT \\
\hline & 3508 & & & & & $* *$ & ++ & -- & - & -- & NT \\
\hline & $3503^{*}$ & & & & & & $* *$ & -- & -- & ++ & NT \\
\hline \multirow[t]{3}{*}{ ST1 } & 8112 & & & & & & & ** & -- & ++ & ++ \\
\hline & 8132 & & & & & & & & $* *$ & -- & -- \\
\hline & $8105^{*}$ & & & & & & & & & ** & ++ \\
\hline
\end{tabular}

a Mutants asterisked were brm mutants.

$b+$, formation of a zone of black microsclerotia on the contact line; - , no formation of a zone of black microsclerotia on the contact line; NT, not tested. Pairing was conducted twice.

Pairings of color mutants of non-tomato pathotype of $V$. dahliae

Five of the 10 isolates of non-tomato pathotype were induced color mutants. Nine alm mutants and eight secreting brm mutants were obtained in these isolates. Non-secreting $\mathrm{brm}$ mutant could not be induced in our experiments. Therefore we could not determine the compatibility and the tester in non-tomato pathotype. Complementation between isolates of the non-tomato pathotype could not be achieved. Although the complementation test among mutants of the non-tomato pathotype could not be achieved, we tried to test complementation between the tomato pathotype and the non-tomato pathotype. Complementary alm-brm pairings did not succeed in any combination between the tomato pathotype and non-tomato pathotype of $V$. dahliae.

\section{DISCUSSION}

We compared the cultural characteristics of $V$. dahliae between the tomato pathotype and the non-tomato pathotype described in Japan by Iijima (14). There were no significant differences in colony growth rate among the isolates. In $V$. albo-atrum, colony growth rates reflected the difference of alfalfa pathotype and potato pathotype (1). However, it was not the same case in Japanese isolates of $V$. dahliae. Puhalla and Hummel (29) reported the relationships of the VCGs to antibiotic resistance. In their experiment, employing sanguinarine nitrate, v-c P2 including seven tomato isolates was sensitive and v-c P5 including four pepper isolates was very resistant. Our isolates also showed a range of sensitivities but the results were not sufficiently definitive to use sensitivity to sanguinarine compounds as a criterion for distinguishing the pathotypes.

We examined three steps to verify the vegetative compatibility: 1) to obtain both alm and brm compatible mutants from each isolate that showed obvious 
complementary reactions of black microsclerotia, 2) to check the selected mutants that must be non-secreting, 3) to pair an alm mutant and a brm mutant (tester) from different isolates.

The results of our experiments suggested the difficulty of using the melaninsynthesis-deficient mutants. For the first step experiment, we obtained the alm-brm complementary mutants from solely three isolates. In the non-tomato pathotype, both complementary alm-brm mutants could not be induced. Thus, the non-tomato pathotype could not confirm the ability of self-compatibility. Although we verified the ability of complementation for these three isolates, the nature of the alm and brm mutants were different. Each alm and brm mutants reacted differently depending on the particular pairing (Table 3). In our experiments, it was impossible to determine the genetical differences from the complementation and culture characteristics. Alm mutants could not be distinguished as alm 1,2 or 3 based on the complementation tests. For brm mutants, Bell et al. (2) distinguished them with the results of complementation tests and culture characteristics on the sucrose-nitrate medium. In $V$. dahliae, the number of loci which control melanin synthesis has not clearly been agreed upon. Bell et al. (2) reported three alm and four brm loci. On the contrary, Kasyanenko and Portenko in 1978 reported that 22 alm, $6 \mathrm{brm}$ and $5 \mathrm{chm}$ loci had been found in $V$. dahliae (10).

At the second step, brm mutants of three self-compatible isolates were nonsecreting. Secreting brm mutants were obtained in some isolates of the non-tomato pathotype (Table 2).

At the final step, three self-compatible isolates of tomato pathotype showed complementation among the isolates. However, other isolates that could uniquely induce alm mutants did not show complementary reaction with these three isolates. At least these three isolates of the tomato pathotype are regarded as the same vegetative compatibility group.

Formations of heterokaryosis was governed by different factors. Heale (11) suggested that many hyphal fusions were required to produce a visible heterokaryotic reaction in combinations with albino-brown microsclerotial color mutants. Our isolates of both the tomato and non-tomato pathotypes showed hyphal anastomoses when each isolate was incubated on water agar. Therefore, isolates with the ability to produce hyphal fusion may fail to yield a sufficient hyphal fusion, as Heale suggested. We wondered if additional mutation occurred in the pathway of melanin synthesis for unsuccessful alm mutants. Pairings between the secreting brm and these alm mutants of the non-tomato pathotype produced black microsclerotia. Thus, the melanin mutants of these isolates were supposed to retain the normal pathway of melanin synthesis. Another impeding factor was incompatibility genes which could exist in either the nucleus or as extrachromosomal factors (34). However it was not the aim of this study to demonstrate the contribution of incompatibility genes.

Mutant induction by a mutagen has the disadvantage of the occurrence of unexpected changes. We are concerned about artificial effects on these complicated 
results. Recently, VCGs of $V$. dahliae using microsclerotial color mutants were reassessed using nitrate non-utilizing (nit) mutants. Many pathotypes were supposed to be compatible by nit mutants $(19,20,32)$. We continue to study the vegetative compatibility relationships among Japanese isolates of $V$. dahliae using nit mutans.

We gratefully thank Dr. A. P. Keinath, Clemson University, U.S.A., for his kind reading of our manuscript and helpful advice. This research was supported in part by a Grant-in-Aid for Encouragement of Young Scientists No. 1760042 (1989) from the Ministry of Education, Science and Culture of Japan.

\section{REFERENCES}

1) Basu, P. K. and Bulter, G., Colony growth response to temperature and pathogenicity of isolates of Verticillium albo-atrum from alfalfa in Canada. Can. J. Plant Pathol., 13, 112-115 (1991).

2) Bell, A. A., Puhalla, J. E., Tolmosoff, W. J., and Stipanovic, R. D., Use of mutants to establish (+)-scytalone as an intermediate in melanin biosynthesis by Verticillium dahliae. Can. J. Microbiol., 22, 787-799 (1976).

3) Brandt, W. H., Morphogenesis in Verticillium: Effects of light and ultraviolet radiation on microsclerotia and melanin. Can. J. Bot., 42, 1017-1023 (1964).

4) Brooker, N. L., Leslie, J. F., and Dickman, M. B., Nitrate non-utilizing mutants of Colletorichum and their use in studies of vegetative compatibility and genetic relatedness. Phytopathology, 81, 672-677 (1991).

5) Correll, J. C., Gordon, T. R., and McCain, A. H., Genetic diversity in California and Florida populations of the pitch canker fungus Fusarium subglutinans $\mathrm{f}$. sp. pini. Phytopathology, 82, 415420 (1992).

6) Croft, J. H. and Jinks, J. L., Aspects of the population genetics of Aspergillus nidulans. In Genetics and Physiology of Aspergillus, ed. by Smith, J. E. and Pateman, J. A., Academic Press, New York (1977), p. 339-360.

7) De Vay, J. and Pullman, G. S., Epidemiology and ecology of diseases caused by Verticillium species, with emphasis on Verticillium wilt of cotton. Phytopathol. Mediterr., 23, 95-108 (1984).

8) Elmer, W. H., Vegetative compatibility groups of Fusarium proliferatum from asparagus and comparisons of virulence, growth rates, and colonization of asparagus residues among groups. Phytopathology, 81, 852-857 (1991).

9) Hagiwara, H., Differentiation of the pathogenicity of Verticillium dahliae in Japan. Plant Prot., 44, 299-303 (1990).

10) Hastie, A. C. and Heale, J. B., Genetics of Verticillium. Phytopathol. Mediterr., 23, 130-162 (1984).

11) Heale, J. B., Verticillium spp., the cause of vascular wilts in many species. In Advances in Plant Pathology, Vol. 6, Genetics of Plant Pathogenic Fungi, ed. by Sidhu, G. S., Academic Press, San Diego (1988), p. 291-312.

12) Heale, J. B. and Isaac, I., Wilt of lucerne caused by species of Verticillium. IV. Pathogenicity of $V$. albo-atrum and $V$. dahliae to lucerne and other crops; Spread and survival of $V$. albo-atrum in soil and in weeds; Effect upon lucerne production. Ann. Appl. Biol., 52, 439-451 (1963).

13) Horiuchi, S., Hagiwara, H., and Takeuchi, S., Host specificity of isolates of Verticillium dahliae towards Cruciferous and Solanaceous plants. In Biological Control of Soil-Borne Plant Pathogens, ed. by Hornby, D., C. A. B International, London (1990), p. 285-298.

14) Iijima, T., Studies on Verticillium wilt of tomato. Bull. Tokyo Metrop. Agric. Exp. Stn., 16, 63-128 (1983). 
15) Iijima, T. and Abe, Z., Occurrence of Verticillium wilt of tomato. Ann. Phytopathol. Soc. Jpn ., 39, 131 (1973).

16) Ingram, R., Verticillium dahliae var. longisporum, a stable diploid. Trans. Br. Mycol. Soc., 51, 339341 (1968).

17) Isaac, I., Verticillium wilt of Brussels spouts. Ann. Appl. Biol., 45, 276-283 (1957).

18) Jackson, C. W. and Heale, J. B., Relationship between DNA content and spore volume in sixteen isolates of Verticillium lecanii and two new diploids of $\boldsymbol{V}$. dahliae $(=\boldsymbol{V}$. dahliae var. longisporum Stark). J. Gen. Microbiol., 131, 3229-3236 (1985).

19) Joaquim, T. R. and Rowe, R. C., Reassessment of vegetative compatibility relationships among pathotypes of Verticillium dahliae using nitrate-non utilizing mutants. Phytopathology, 80, 11601166 (1990).

20) Joaquim, T. R. and Rowe, R. C., Vegetative compatibility and virulence of pathotypes of Verticillium dahliae from soil and potato plants. Phytopathology, 81, 552-558 (1991).

21) Nagao, H., Taguchi, T., Nishimura, K., Tanaka, R., and Horiuchi, S., Ploidy analysis for Verticillium dahliae by flow cytometry. Proc. 35th Anniversary Meet. Mycol. Soc. Jpn, p. 47 (1991).

22) Nelson, R., The specific pathogenesis of the Verticillium that causes wilt of peppermint. Phytopathology, 37, 17 (1947).

23) O'Garro, L. W. and Clarkson, J. M., Heterokaryon incompatibility and heterozygous diploid production in tomato wilt isolates of Verticillium dahliae. J. Gen. Microbiol., 134, 2977-2984 (1988).

24) Pegg, G. F., Verticillium diseases. Rev. Plant Pathol., 53, 157-182 (1974).

25) Presley, J. T., Growth response of Verticillium albo-atrum to sanguinarine in nutrient agar. Phytopathology, 59, 1968-1969 (1969).

26) Puhalla, J. E., Differences in sensitivity of Verticillium species to ultraviolet irradiation. Phytopathology, 63, 1488-1492 (1973).

27) Puhalla, J. E., Classification of isolates of Verticillium dahliae based on heterokaryon incompatibility. Phytopathology, 69, 1186-1189 (1979).

28) Puhalla, J. E., A visual indicator of heterokaryosis in Fusarium oxysporum from celery. Can. J. Bot., 62, 540-545 (1984).

29) Puhalla, J. E. and Hummel, M., Vegetative compatibility groups within Verticillium dahliae. Phytopathology, 73, 1305-1308 (1983).

30) Puhalla, J. E. and Mayfield, J. E., The mechanism of heterokaryotic growth in Verticillium dahliae. Genetics, 76, 411-422 (1974).

31) Puhalla, J. E. and Spieth, P. T., A comparison of heterokaryosis and vegetative incompatibility among varieties of Gibberella fujikuroi (Fusarium moniliforme). Exp. Mycol., 9, 39-47 (1985).

32) Strausbaugh, C. A., Schroth, M. N., Weinhold, A. R., and Hancock, J. G., Assessment of vegetative compatibility of Verticillium dahliae tester pathotypes and isolates from California potatoes. Phytopathology, 82, 61-68 (1992).

33) Takeda, K., Ishizuka, T., and Akanuma, R., Classification of the pathogen of Verticillium yellows of celery by pathogenicity. Proc. Kanto-Tosan Plant Prot. Soc., 35, 71-72 (1988).

34) Typas, M. A., Heterokaryon incompatibility and interspecific hybridization between Verticillium albo-atrum and Verticillium dahliae following protoplast fusion and microinjection. J. Gen. Microbiol., 129, 3043-3056 (1983).

35) Venter, S. L., Theron, D. J., Steyn, P. J., Ferreira, D. I., and Eicker, A., Relationship between vegetative compatibility and pathogenicity of isolates of Fusarium oxysporum f. sp. tuberosi from potato. Phytopathology, 82, 858-862 (1992).

36) Wheeler, M. H., Tolmsoff, W. J., and Meola, S., Ultrastructure of melanin formation in Verticillium dahliae with (+)-scytalone as a biosynthetic intermediate. Can. J. Microbiol., 22, 702-711 (1976). 